\title{
Changes in haematology during upstream migration in American shad
}

\author{
J. B. K. LEONARD* AND S. D. MCCORMICK \\ S.O. Conte Anadromous Fish Research Center, Biological Resources Division, \\ U.S. Geological Survey, Turners Fall, MA 01376 U.S.A. and Department of Biology, \\ University of Massachusetts, Amherst, MA 01003, U.S.A.
}

(Received 6 November 1998, Accepted 16 February 1999)

\begin{abstract}
Heart mass of American shad Alosa sapidissima did not change during migration in the Connecticut River. Spleen mass decreased and there was an increase in available blood haemoglobin $(+22 \%)$ and haematocrit $(+9 \%)$. The decreases in spleen somatic index $(-29 \%)$ and spleen haemoglobin content $(-15 \%)$ were dependent upon distance travelled upriver and not seasonal migration timing or short-term exercise events such as passage up a fish ladder. There was no effect of migration timing on any of the blood parameters measured, suggesting that any physiological responses during migration were based on distance travelled rather than seasonally variable conditions such as temperature, although blood haemoglobin $(+24 \%)$ and haematocrit $(+21 \%)$ increased after passage up a fish ladder. These changes in haematological physiology occurring during upstream migration may increase swimming performance and migratory success in American shad.

(C) 1999 The Fisheries Society of the British Isles
\end{abstract}

Key words: migration; spleen; $\mathrm{O}_{2}$ carrying capacity; American shad; Alosa sapidissima; blood.

\section{INTRODUCTION}

The upstream, spawning migration is a crucial life history event for adult anadromous fishes. The capacity for upstream locomotion is therefore critical and the individual employs tactics that increase the likelihood of reproductive success. In the American shad Alosa sapidissima (Wilson) spawning may occur repeatedly as the fish continues to move upstream in its natal river. If American shad increase fecundity by increasing the distance travelled from the mouth of the river enabling repeated spawning bouts (Glebe \& Leggett, 1981), then there would be a selective advantage for an adult to be able to swim efficiently and effectively since this should increase the total transit distance possible. The benefits of increased swimming performance may also be independent of distance travelled and serve to increase the ability of individuals to traverse barriers, avoid predators and participate in spawning. Maximum swimming capacity may also be important during migration although this is unlikely to be the most energetically efficient behaviour (Videler \& Nolet, 1990; Dewar \& Graham, 1994).

Upstream anadromous migration is typically energetically costly and uses stored lipid and protein as an energy source (Beamish et al., 1979; Crawford

\footnotetext{
*Author to whom correspondence should be addressed at: S.O. Conte Anadromous Fish Research
} Center, 1 Migratory Way, Turners Falls, MA 01376, U.S.A. 
et al., 1986; Jonsson et al., 1997). In order to increase the efficiency of migration, many species alter the capacity of their metabolic enzyme systems (Guderley et al., 1986; Leonard \& McCormick, 1999) and also change their patterns of energy utilization (Leonard, 1997).

Another way to increase the likelihood of migratory success of fish is to modify the oxygen carrying and cardiovascular systems to increase the capacity to swim under rigorous conditions. This might be accomplished by changing available haemoglobin levels or by altering cardiac performance itself. Heart mass increases during the breeding season in response to 11-ketotestosterone in male rainbow trout Oncorhynchus mykiss Walbaum (Thorarensen et al., 1996). Exercise also elicits isometric heart growth (Farrell et al., 1990) and greater maximum cardiac output and power output (Farrell et al., 1991) in rainbow trout. Migration could function as an extended exercise training regime rather than a starvation event, although the aptness of this analogy still needs to be demonstrated, since the physiological responses to exercise and starvation are very different (Blasco et al., 1992; Collins \& Anderson, 1995; Davison, 1998). Further, certain reaches of a river, particularly those including fish ladders, waterfalls or steep gradients, could be considered as inducing acute bouts of exercise.

Although changes in cardiovascular parameters have been hypothesized to be linked to increased locomotory performance, experiments with exercise training in fish have shown that there are seldom increases in critical swimming speed during exercise training (e.g. Farrell et al., 1991; for an exception see Young \& Cech, 1994). Nonetheless, increases in heart size, stroke volume and cardiac metabolic enzymes in these studies suggest that there are probably exerciselinked signals leading to changes in the cardiovascular system (Farrell et al., 1991). Similarly, the large heart sizes and stroke volumes of scombroid fishes are thought to be adaptations to the high swimming speeds and performance levels in this group (Farrell, 1996). Extreme locomotory activity can also influence the capacity to carry oxygen (Black et al., 1966). There is also evidence to suggest that decreased haematocrit can decrease maximal oxygen uptake and critical swimming speeds and that, within limits, increased haematocrit can increase maximal oxygen uptake (Gallaugher et al., 1995) demonstrating a potential increase in performance with changing haematological variables. However, any increase in oxygen carrying capacity based on increased red cell volume would increase blood viscosity and probably increase the energetic costs of circulation (Houston et al., 1996a).

The American shad is an abundant anadromous fish native to the eastern coast of the U.S.A. Adults spawn in the main-stems of rivers in the spring and juveniles migrate downstream to the sea in the autumn of their hatching year. Typically, adults return to their natal river 3-7 years after hatching. American shad seem to be extremely sensitive to low dissolved oxygen levels, although this is based on anecdotal observations of the fish in captivity and in transport situations. They also possess high concentrations of red blood cells compared to other teleosts, including other anadromous clupeids (Blake, 1981). Since these observations were based on American shad beginning their upstream migration, it is unclear if they are unique to shad or if shad haematological parameters acclimate during migration. 
This study investigated the possibility that migrating adult American shad may be responding to the respiratory stress and energetic demands of migration during the migratory period by modifying the cardiac or haematological systems. This hypothesis was examined with respect to migratory distance, seasonal timing and fish ladder passage.

\section{MATERIALS AND METHODS}

\section{EXPERIMENT I}

In order to assess the changes in cardiac and blood parameters occurring as American shad migrate upstream during their spawning migration, adult shad were sampled in the Connecticut River during spring 1993 and 1994 at four sites in the Connecticut River. Fish were captured at Old Lyme, CT (river km 1), Holyoke Dam Facility, Northeast Utilities, Holyoke, MA (river km 139), Cabot Station/Turners Falls Dam Complex, Northeast Utilities, Turners Falls, MA (river km 198) and Vernon Dam, New England Power Co., Vernon, VT (river km 228). At Old Lyme, fish were captured with gillnets (12.7- and $14 \cdot 0-\mathrm{cm}$ monofilament stretch mesh). At all other sites, fish were taken from traps in the fish passage facilities. Fish were held in these traps for $<20 \mathrm{~min}$. Fish were collected within 1 week of their first appearance at each site ( 2 weeks at Old Lyme) in order to sample the first cohort passing through the Connecticut River. This was done to select preferentially animals that chose a direct course of migration upriver and thus reduce variation introduced by fish with variable migration speeds. At each site $c .20$ fish were sampled (10 males and 10 females). Fish were anaesthetized with MS-222 (tricaine methansulphonate; $50 \mathrm{mg}^{-1}, \mathrm{pH} \mathrm{7 \cdot 0)}$, bled immediately from the caudal vessels into a heparinized syringe and placed on ice. A sub-sample of vascular blood was frozen immediately on dry ice and transferred to a $-80^{\circ} \mathrm{C}$ freezer for measurement of haemoglobin content. Another sub-sample of blood was transferred to a heparinized capillary tube and spun at $13500 \mathrm{~g}$ for $5 \mathrm{~min}$ in a microhaematocrit centrifuge for haematocrit (Hct) determination. Fish were brought back to the laboratory within $30 \mathrm{~min}$ and length and weight was recorded. Hearts, gonads and, in 1994, spleens were removed, weighed and frozen at $-80^{\circ} \mathrm{C}$. Hearts were carefully excised posterior to the bulbus arteriosus and anterior to the sinus venosus. Blood within the heart chambers was removed by blotting.

Blood haemoglobin concentration $(\mathrm{Hb})$ was measured by the cyanomethaemoglobin method (Van Kampen \& Zijlstra, 1961) using Sigma kit no. 525 which was read at $550 \mathrm{~nm}$ in a microplate spectrophotometer. Spleen haemoglobin content $(\mathrm{sHb})$ was measured using the same method except that spleens were homogenized in an appropriate dilution of Drabkin's reagent with a homogenizer and then sonicated for two 5-s bursts at $100 \%$ power (Braunsonic, B. Braun Instruments, South San Francisco, CA, U.S.A.). Spleen haemoglobin levels were determined spectrophotometrically at both 550 and $650 \mathrm{~nm}$ to correct for tissue interference.

Cardiosomatic index $\left(I_{\mathrm{C}}\right)$ was determined to be the per cent of non-gonadal body mass represented by the heart. Because fish are losing body mass during migration, the cardiosomatic length index $\left(I_{\mathrm{CL}}\right)$ was calculated as 100 (heart mass) $L_{\mathrm{F}}{ }^{-1}$. Mean erythrocyte haemoglobin content (MEHC) represents the amount of haemoglobin present in $100 \mathrm{ml}$ of concentrated red cells (calculated as $\mathrm{Hb} \mathrm{Hct}^{-1}$ ). Spleen somatic index $\left(I_{\mathrm{S}}\right)$ was determined to be the per cent of non-gonadal mass represented by the spleen. Spleen somatic length index $\left(I_{\mathrm{SL}}\right)$ was calculated as 100 (spleen mass) $L_{\mathrm{F}}{ }^{-1}$. Non-gonadal condition factor was determined by the following equation: 100(total body mass - gonad mass) $\left.\times L_{\mathrm{F}}{ }^{-3}\right]$.

On 7 May 199518 fish (11 female, seven male) were sampled by gillnet off Barnagut Light, NJ, aboard a commercial gillnetting vessel in order to compare the results of river migrating fish to fish still in the ocean. After capture, the fish were sampled using the same protocol as used in 1994. These animals were migrating up the east coast and were maturing $\left[I_{\mathrm{G}} ;\right.$ male $=6.82 \pm 0.59$ (S.E.), female $\left.=12 \cdot 79 \pm 0 \cdot 98\right]$. Since these fish were not 
sampled in the same years as the Connecticut River migrants and we could not determine definitively which river they were navigating toward, these oceanic fish were not included in the overall statistical analysis, but were compared with fish from Old Lyme (1993 and 1994; river $\mathrm{km} \mathrm{1)}$.

\section{EXPERIMENT II}

In order to determine whether blood and cardiac parameters were altered dependent upon individual migration timing, adult fish were captured at the Cabot Station facility of the Northeast Utilities Turners Falls Dam complex in Turners Falls, MA, U.S.A. (river km 198) during the early, middle and late portions of the adult shad migrations in 1993 and 1994. Fish were taken from a trapping facility at the top of the ladder. Early samples were taken within 1 week of the appearance of shad at the ladder (13 May 1993 and 26 May 1994). Mid-run samples were taken arbitrarily when large numbers of fish were observed in the ladder and many fish were passing successfully through the ladder (7 and 8 days after early sampling in 1993 and 1994, respectively). Late samples were taken when the number of fish passing through the facility had dropped dramatically from peak levels (19 and 14 days after peak sampling in 1993 and 1994, respectively). At each time point 20 fish were sampled (10 male and 10 female). Tissue sampling and analysis was as described for experiment I.

\section{EXPERIMENT III}

In an effort to determine whether cardiac and haematological parameters are altered by traversing a fish ladder, adult shad were captured (eight males, nine females) from the base of the Cabot Station fish ladder (river km 198) in May, 1995 and compared with animals captured on the same day (10 males, 10 females) from the trap located at the top of the ladder. Fish from below the dam were captured by snagging with a fishing pole and a large treble hook. Fish were snagged directly out of the tailrace within $c .20 \mathrm{~m}$ of the entrance to the ladder. This area was characterized by a strong current produced by the attraction flow for the ladder and it was assumed that fish in this area were attempting to enter the ladder. The time from snagging to completion of blood sampling was $<2$ min. After capture the fish were sampled as described above for fish captured in 1994.

\section{STATISTICS}

Data were analysed using multi-way analysis of covariance (ANCOVA) using fork length as a covariant (SAS Institute, Inc, Cary, NC, U.S.A.) with sampling year, sex and sampling site as independent variables. Values are reported as mean \pm standard error (S.E.). Data were normally distributed and exhibited homogeneous variances. Data were analysed further using least-squares multiple comparisons testing when appropriate. Using length as a covariant was appropriate since shad are secondarily sexually dimorphic relative to length and since locomotory costs and impacts may vary with length.

\section{RESULTS}

\section{EXPERIMENT I}

A small (15\%), but significant, increase in $I_{\mathrm{C}}$ was detected between $\mathrm{km} 1$ $(0 \cdot 26 \pm 0.009)$ and $\mathrm{km} 139(0 \cdot 30 \pm 0 \cdot 008)(P=0 \cdot 0416)$. Upriver sites demonstrated no further change in $I_{\mathrm{C}}$. Evaluation of $I_{\mathrm{C}}$ showed interactions between sampling location and sex $(P=0.031)$ and between sampling location, sex and year of sampling $(P=0.009)$. Since body mass changed over the course of migration, changes in heart weight were examined with respect to fork length. When heart mass was indexed to length using $I_{\mathrm{CL}}$ there was a significant decrease $(P=0.0012)$ in $I_{\mathrm{CL}}$ as fish moved upstream. However, multiple-regression analysis of heart mass relative to $L_{\mathrm{F}}$ indicated no significant changes in heart 

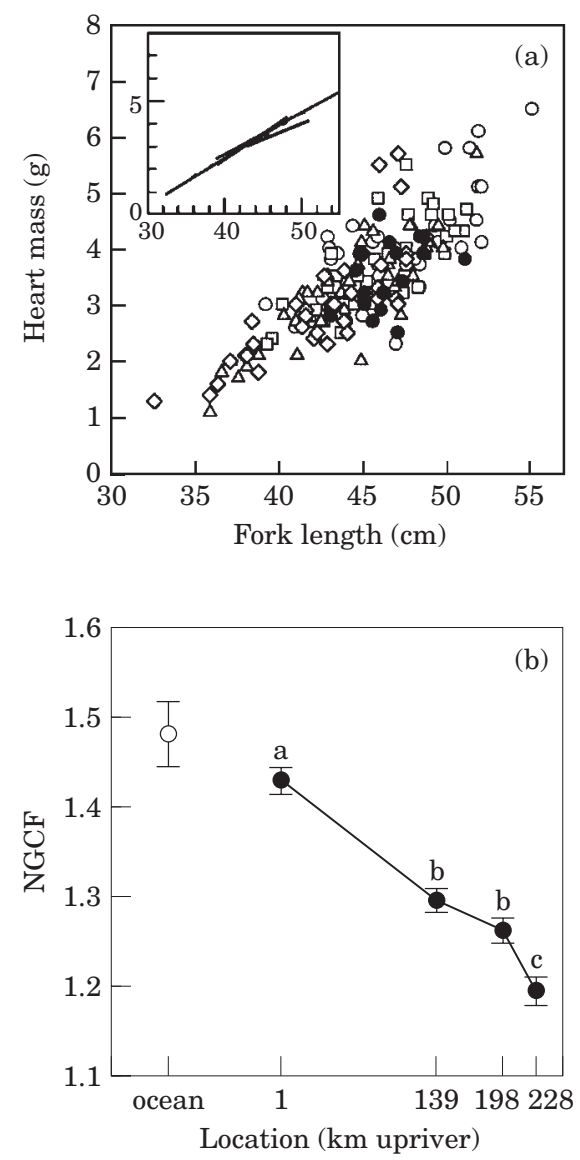

FIG. 1. (a) Relationship between fork length and heart mass in migrating American shad (experiment I). Regression lines (inset box) are not significantly different from each other $(P>0 \cdot 05)$.

Ocean-Barnagut Light NJ; $\bigcirc-$, Old Lyme-km 1; $\square---$, Holyoke Dam-km 139; $\triangle \cdots$, Cabot Station-km 198; - - - , Vernon Dam-km 228. (b) Relationship between sampling site location and non-gonadal condition factor (NGCF) for experiment I. O, Riverine NGCF; $\bigcirc$, oceanic NGCF. Error bars are 1 s.E. Letters indicate significant differences between riverine sampling sites.

mass as the fish moved upstream [Fig. 1(a); $P_{\text {location }}=0$.89]. This indicated that heart size itself was not changing, but that fish body mass was decreasing as fish moved upstream, in a manner related to the length of the individual. Therefore, $I_{\mathrm{C}}$ was misleading because of the loss of body mass with increasing distance upriver. $I_{\mathrm{CL}}$ was also misleading because the fish sampled at the upriver sites were smaller than those sampled further downstream. There was a significant decrease in non-gonadal condition factor from $1.43 \pm 0.014$ at $\mathrm{km} 1$ to $1.20 \pm 0.02$ at km 228 [Fig. 1(b); $P<0.0001$ ]. There was no difference in $I_{\mathrm{C}}$ or heart weight between ocean fish and fish captured at $\mathrm{km} 1$.

Blood haemoglobin content increased progressively over the course of migration, with a $22 \%$ increase between $\mathrm{km} 1$ and the most upriver sampling site (river $\mathrm{km} 228$ ) at Vernon Dam [Fig. 2(a); $P=0 \cdot 0001]$. There was no significant difference in blood haemoglobin content between the estuary $(\mathrm{km} \mathrm{1)}$ and the ocean fish. 

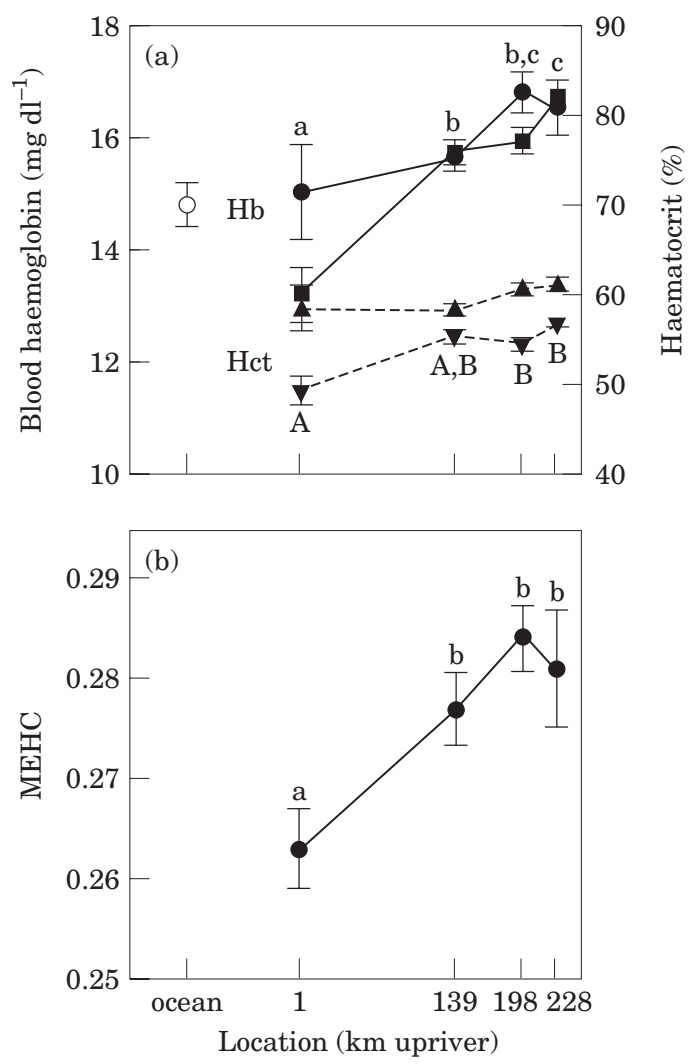

FIG. 2. (a) Relationship between sampling site location and blood haemoglobin and haematocrit of migrating adult American shad (experiment I). @, River male blood haemoglobin content; river female blood haemoglobin content; $\bigcirc$, oceanic blood haemoglobin content (both sexes pooled); $\boldsymbol{\Delta}$, male haematocrit; $\boldsymbol{\nabla}$, female haematocrit. Error bars are 1 s.E. Letters indicate significant differences between riverine sampling sites. (b) Mean erythrocyte haemoglobin content (MEHC) pooled for all fish from experiment I. Letters indicate significant differences between riverine sampling sites. Error bars are 1 S.E.

Haematocrit was related significantly to distance travelled upriver, increasing at upriver sites by $9 \%$ [Fig. 2(a)]. Male haematocrits $(60 \% \pm 0 \cdot 5)$ were significantly higher $(P=0 \cdot 0002)$ than female $(54 \% \pm 0 \cdot 7)$. Mean erythrocyte haemoglobin content increased with distance upriver in this experiment from $0 \cdot 26 \pm 0.003$ at $\mathrm{km} 1$ to $0 \cdot 28 \pm 0.006$ at $\mathrm{km} 228$ and averaged $0 \cdot 26 \pm 0.006$ overall [Fig. 2(b); $P=0 \cdot 0052$ ].

$I_{\mathrm{S}}$ showed significant differences between sites $(P=0.0169)$ and sexes $(P=0 \cdot 0434)$. There was a general decrease in $I_{\mathrm{S}}$ with increasing distance upriver [Fig. 3(a)]. Females appeared to reach a low $I_{S}$ plateau at a more downriver location than the males. $I_{\mathrm{SL}}$ also decreased with increasing distance upriver $(P=0.0012)$. When spleen mass was related to fork length using regression analysis [Fig. 3(b)] there was also a significant effect of sex $(P=0.0034)$ and sampling site $(P=0.008)$ on spleen haemoglobin content. Both sexes demonstrated a decrease in spleen haemoglobin from Old Lyme to upriver sites [Fig. 3(a)]. Females generally had lower levels than males although there was no difference between the sexes at the most upriver sampling site. There was also a 

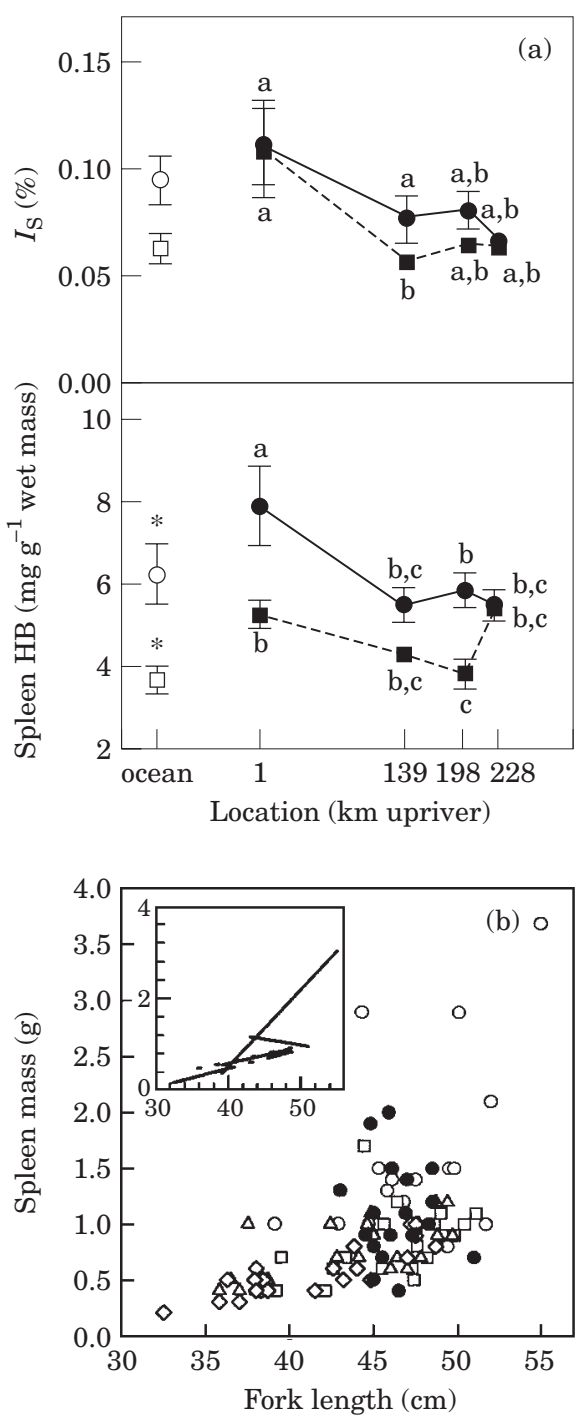

FIG. 3. (a) Relationship between sampling site location and spleen haemoglobin content (spleen $\mathrm{Hb}$ ) and spleen somatic index $\left(I_{\mathrm{S}}\right)$ for experiment I. $\bullet$, Male riverine $I_{\mathrm{S}}$ or spleen $\mathrm{Hb} ; \boldsymbol{\square}$, female riverine $I_{\mathrm{S}}$ or spleen $\mathrm{Hb} ; \bigcirc$, male oceanic $I_{\mathrm{S}}$ or spleen $\mathrm{Hb}$; $\square$, female oceanic $I_{\mathrm{S}}$ or spleen $\mathrm{Hb}$. Error bars are 1 s.E. Letters indicate significant differences between riverine sampling sites. Stars indicate significant differences between oceanic and river km 1 sampling sites. (b) Relationship between fork length and spleen weight for experiment I. Old Lyme regression line (inset box) is significantly different from all others $(P=0.023) . \quad \mathbf{-}_{-} \cdot \cdots$, Ocean-Barnagut Light $\mathrm{NJ} ; \bigcirc-$, Old Lyme - km 1; $\square---$, Holyoke Dam-km 139; $\triangle \cdots$, Cabot Station-km 198; $-\cdot-\cdot$, Vernon Dam-km 228.

significant interaction between sampling site and sex for this parameter $(P=0.034)$. There was no significant difference in either $I_{\mathrm{S}}$ or spleen weight between the ocean and Old Lyme. However, spleen haemoglobin level was significantly lower in ocean fish and the sex difference in river fish was also present in ocean fish. 

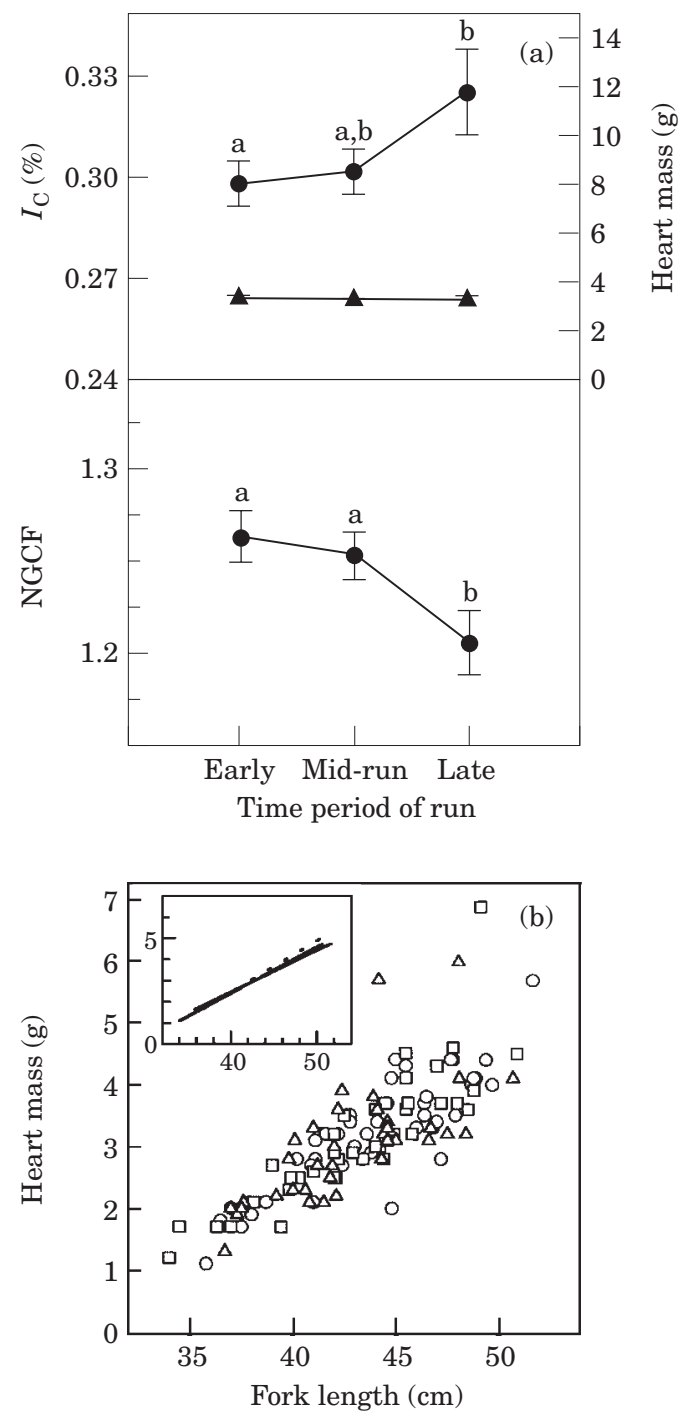

FIG. 4. (a) Relationship between cardiosomatic index $\left(I_{\mathrm{C}}\right)$, heart mass, non-gonadal condition factor (NGCF) and sampling time for migratory adult American shad (experiment II).,$I_{\mathrm{C}}$ or NGCF; $\boldsymbol{\Delta}$, heart mass. Error bars are 1 S.E. Letters indicate significant differences between sampling times. (b) Relationship between fork length and heart mass for experiment II. Regression lines (inset box) are not significantly different. $\bigcirc —$, Early migrants; $\square---$, mid-run migrants; and $\triangle \cdots$, late migrants.

\section{EXPERIMENT II}

Relative heart size as measured by $I_{\mathrm{C}}$ was significantly larger in fish sampled during the late portion of the migration $[P=0.039$; Fig. 4(a)]. There was also a significant interaction between sampling year and sampling time $(P=0.029)$. However, this change in $I_{C}$ can again be explained by the decrease in body mass that occurred late in migration, since there was no effect of migration time on heart weight relative to fork length [Fig. 4(b)]. Non-gonadal condition factor decreased significantly $(P=0.004)$ over the migratory period [Fig. 4(a)]. 
Blood haemoglobin levels did not differ as a function of migratory timing. There was, however, a significant difference between sexes $(P=0.0003)$ with males averaging $16 \cdot 3 \pm 0.23 \mathrm{~g} \mathrm{dl}^{-1}$ and females averaging $15 \cdot 5 \pm 0 \cdot 20 \mathrm{~g} \mathrm{dl}^{-1}$. Haematocrit did not differ between sampling times, but differed between sexes and sampling years. Males averaged haematocrit levels of $60 \pm 0.7 \%$ and $58 \pm 1 \cdot 1 \%$ in 1993 and 1994, respectively. Females had values of $55 \pm 1 \cdot 0 \%$ and $53 \pm 1 \cdot 0 \%$ in 1993 and 1994 . There was also a significant interaction between year and time $(P=0.001)$ for haematocrit. MEHC showed no effect of sampling time or sex, differing only between the two sampling years $(P=0 \cdot 0093)$; there was a significant interaction between year and sampling time $(P=0 \cdot 0165)$.

There was no effect of sampling time on $I_{S}$, nor did the sexes differ significantly. The concentration of haemoglobin in the spleen did differ significantly between the sexes $(P=0 \cdot 0005)$ with males having higher levels, although there was no effect of sampling time.

\section{EXPERIMENT III}

There was no difference between fish captured at the bottom and the top of the ladder in $I_{\mathrm{C}}$ (bottom $0 \cdot 3 \pm 0 \cdot 02$, top $0 \cdot 3 \pm 0 \cdot 01 \%$ ), heart mass (bottom $3 \cdot 8 \pm 0 \cdot 4$, top $3 \cdot 5 \pm 0 \cdot 2 \mathrm{~g}$ ), $I_{\mathrm{S}}$ (bottom $0 \cdot 07 \pm 0 \cdot 01$, top $0 \cdot 06 \pm 0 \cdot 002 \%$ ) or spleen $\mathrm{Hb}$ (bottom $4 \cdot 3 \pm 0 \cdot 4$, top $\left.3 \cdot 8 \pm 0 \cdot 2 \mathrm{mg} \mathrm{g}^{-1}\right)$. Haematocrit $(P=0 \cdot 0001 ; 21 \%)$ and blood haemoglobin levels $(P=0.0001 ; 24 \%)$ were significantly higher at the top of the fish ladder than at the bottom [Hct: bottom 47.6 $\pm 1 \cdot 6$ (male), 40.9 \pm 1.4 (female), top $56 \cdot 1 \pm 1 \cdot 4$ (male), $50 \cdot 5 \pm 1 \cdot 3 \%$ (female); $\mathrm{Hb}$ : bottom $12 \cdot 0 \pm 0 \cdot 5$, top $\left.14 \cdot 8 \pm 0 \cdot 2 \mathrm{mg} \mathrm{dl}^{-1}\right]$.

\section{DISCUSSION}

Heart size has a direct effect on cardiac output and stroke volume and has been shown to increase with exercise training (Farrell et al., 1990, 1991; Thorarensen et al., 1996). In the present study an increase in $I_{\mathrm{C}}$ was found during migration, but this change was due primarily to the decrease in body mass of shad at upstream sites. When regressed on length there was no effect of migration on heart size. It is possible, however, that some advantage may be gained even in this instance. Functionally, fish from Vernon, VT (km 228) of the same length, but lower body mass, than their counterparts at Old Lyme, CT $(\mathrm{km}$ 1) were propelling less mass though the water. This means that they had a greater cardiac output available relative to constant mass, perhaps increasing the efficiency of power output to some degree. It has been suggested that growth of the teleost heart is modified by multiple interacting factors including water temperature, whole body growth rate and food intake relative to energy expenditure as well as cardiac work load (Farrell et al., 1988). In migrating American shad, these factors may be interacting with the effects of increased work load. The apparent net effect is no significant increase in cardiac mass (perhaps because of the lack of fuel available for growth) even though the cardiac work load is likely to increase during migration.

Results from experiment I suggest that shad increase respiratory capacity during migration by drawing on a pool of stored red blood cells from the spleen. Whole blood $\mathrm{Hb}$ levels and Hct rise at upriver sampling sites while spleen size 
and haemoglobin content decrease. Elevation of Hct above normal values has resulted in increased maximal oxygen uptake in rainbow trout (Gallaugher et al., 1995) and the American shad in this study may benefit in a similar manner. The results of experiment III suggest that the splenic response was a consequence of the upriver migration itself rather than an effect of fish ladder passage at the upstream sampling sites. If Hct and $\mathrm{Hb}$ were both higher at the top of the ladder and were accompanied by concomitant decreases in $I_{\mathrm{S}}$ and $\mathrm{sHb}$, a splenic response to ladder ascension would be suggested. In this case, Hct and $\mathrm{Hb}$ were higher at the top of the ladder, but there were no changes in spleen parameters. The elevated Hct and $\mathrm{Hb}$ may have been a characteristic of fish successful in passing the ladder as compared to the many fish that did not ascend the structure successfully, but did not suggest a use of the spleen response while in the ladder. Yamamoto (1988) reported spleen contraction in response to exercise within 3-5 min in a variety of freshwater fishes and within $30 \mathrm{~min}$ in several cyprinid species (Yamamoto, 1987). In both cases he saw a concomitant decrease in spleen haemoglobin content and increase in blood haemoglobin levels. Additionally, splenectomy has decreased blood oxygen content in rainbow trout swimming at maximal sustained speeds (Gallaugher et al., 1992) and, although it did not appear to affect the magnitude of maximum critical swimming speed, might be detrimental for extended periods of time. It is possible that the pronephros also serves as a secondary reservoir for red blood cells as has been shown in goldfish Carassius auratus L. (Houston et al., 1996b), but there is no information regarding this tissue in American shad. Present data demonstrate that a splenic response was occurring as a result of the overall migration while there may have been increased passage success for individuals with high oxygen carrying capacity at obstacles within the overall migration.

American shad followed a differing pattern in splenic response between the sexes with males demonstrating a lesser decrease in spleen weight and spleen haemoglobin content than females with distance travelled upriver. Yamamoto \& Itazawa (1989) noted a similar pattern in carp Cyprinus carpio L., and observed that males had consistently higher spleen weights and spleen haemoglobin contents than did females and that this relationship remained constant even though spleen weights and haemoglobin levels changed seasonally. Sexual dimorphism in Hct has been shown in other fish species including anadromous brook trout Salvelinus fontinalis Mitchill (McCormick \& Naiman, 1985), pike Esox lucius L. (Mulcahy, 1970), rainbow trout (Sano, 1960) and largemouth bass Micropterus salmoides Lacépède (Steuke \& Atherton, 1965). There is some suggestion that this sex difference may be linked to spermiation in male fish (McCormick \& Naiman, 1985). It is interesting to examine this splenic dimorphism in shad given that the species also displays a sexual length dimorphism. Perhaps the greater splenic response in females is related to the larger stored energy depletion in large shad (Leonard, 1997) since both are indicative of migration being more rigorous for female American shad.

There appeared to be little effect of migration time on haematological and cardiac systems indicating that the controlling factors influencing passage rates late in the season and affecting the eventual end of the migratory run may not have been capable of modifying the oxygen carrying system beyond the scope already affected by migration distance. American shad may be unable to 
increase further oxygen availability to the tissues in the later portions of the run even though warmer river water temperatures would tend to make less oxygen available to migrating fish who would presumably be requiring more oxygen at higher temperatures. Further elevation of the red cell component of the blood could increase viscosity to a level that is energetically or functionally prohibitive (see Houston et al., 1996a).

This study demonstrated the responsiveness of the cardiac and haematological systems, particularly the erythrocyte control system, to migration. It has demonstrated a modification of the oxygen carrying system that potentially increases migratory success in the American shad. It is suggested that there are limits to the scope of this responsiveness and that other factors may be influencing oxygen carrying capacity. Further work on the modification of cardiac and haematological systems during exercise and migration would be instructive in understanding the physiological dynamics supporting this critical behaviour in anadromous fishes.

The authors thank M. Sheridan, G. Barbin, D. Pugh and the MA Fish and Wildlife Cooperative Research Unit, R. Allen and the New Jersey Department of Environmental Protection, K. Cox and the Vermont Department of Fish and Wildlife, Northeast Utilities, New England Electric Co., H. Root, the crew of the F.V. Compromise and the students and staff of the S.O. Conte Anadromous Fish Research Center for their help in conducting this study.

\section{References}

Beamish, F. W. H., Potter, I. C. \& Thomas, E. (1979). Proximate composition of the adult anadromous sea lamprey, Petromyzon marinus, in relation to feeding, migration and reproduction. Journal of Animal Ecology 48, 1-19.

Black, E. C., Manning, G. E. \& Hayashi, K. (1966). Changes in levels of hemoglobin, oxygen, carbon dioxide, pyruvate, and lactate in venous blood of rainbow trout (Salmo gairdneri) during and following severe muscular activity. Journal of the Fisheries Research Board of Canada 23, 783-795.

Blake, M. M. (1981). Blood properties of pre- and postspawning shad, blueback herring, and menhaden. M.S. thesis, University of Bridgeport.

Blasco, J., Fernandez, J. \& Gutierrez, J. (1992). Fasting and refeeding in carp, Cyprinus carpio L.: the mobilization of reserves and plasma metabolite and hormone variations. Journal of Comparative Physiology B 162, 540-546.

Collins, A. L. \& Anderson, T. A. (1995). The regulation of endogenous energy stores during starvation and refeeding in the somatic tissues of the golden perch. Journal of Fish Biology 47, 1004-1015.

Crawford, R. H., Cusack, R. R. \& Parlee, T. R. (1986). Lipid content and energy expenditure in the spawning migration of alewife (Alosa pseudoharengus) and blueback herring (Alosa aestivalis). Canadian Journal of Zoology 64, 1902-1907.

Davison, W. (1998). The effects of exercise training on teleost fish, a review of recent literature. Comparative Biochemistry and Physiology 117A, 67-75.

Dewar, H. \& Graham, J. B. (1994). Studies of tropical tuna swimming performance in a large water tunnel. I. Energetics. Journal of Experimental Biology 192, 13-31.

Farrell, A. P. (1996). Features heightening cardiovascular performance in fishes, with special reference to tunas. Comparative Biochemistry and Physiology 113A, 61-67.

Farrell, A. P., Hammons, A. M., Graham, M. S. \& Tibbits, G. F. (1988). Cardiac growth in rainbow trout, Salmo gairdneri. Canadian Journal of Zoology 66, 2368-2373.

Farrell, A. P., Johansen, J. A., Steffensen, J. F., Moyes, C. D., West, T. G. \& Suarez, R. K. (1990). Effects of exercise training and coronary ablation on swimming 
performance, heart size, and cardiac enzymes in rainbow trout, Oncorhynchus mykiss. Canadian Journal of Zoology 68, 1174-1179.

Farrell, A. P., Johansen, J. A. \& Suarez, R. K. (1991). Effects of exercise-training on cardiac performance and muscle enzymes in rainbow trout, Oncorhynchus mykiss. Fish Physiology and Biochemistry 9, 303-312.

Gallaugher, P., Axelsson, M. \& Farrell, A. P. (1992). Swimming performance and haematological variables in splenectomized rainbow trout, Oncorhynchus mykiss. Journal of Experimental Zoology 171, 301-314.

Gallaugher, P., Thorarensen, H. \& Farrell, A. P. (1995). Haematocrit in oxygen transport and swimming in rainbow trout (Oncorhynchus mykiss). Respiratory Physiology 102, 279-292.

Glebe, B. D. \& Leggett, W. C. (1981). Temporal, intra-population differences in energy allocation and use by American shad (Alosa sapidissima) during the spawning migration. Canadian Journal of Fisheries and Aquatic Sciences 38, 795-805.

Guderley, H., Blier, P. \& Richard, L. (1986). Metabolic changes during the reproductive migration of two sympatric coregonines, Coregonus artedii and Coregonus clupeaformis. Canadian Journal of Fisheries and Aquatic Sciences 43, 1859-1865.

Houston, A. H., Dobric, N. \& Kahurananga, R. (1996a). The nature of hematological response in fish. Fish Physiology and Biochemistry 15, 339-347.

Houston, A. H., Roberts, W. C. \& Kennington, J. A. (1996b). Hematological response in fish: pronephric and splenic involvements in the goldfish, Carassius auratus L. Fish Physiology and Biochemistry 15, 481-489.

Jonsson, N., Jonsson, B. \& Hansen, L. P. (1997). Changes in proximate composition and estimates of energetic costs during upstream migration and spawning in Atlantic salmon, Salmo salar. Journal of Animal Ecology 66, 425-436.

Leonard, J. B. K. (1997). The energetics of upstream migration in adult American shad (Alosa sapidissima) in the Connecticut River. Ph.D. dissertation, University of Massachusetts, Amherst.

Leonard, J. B. K. \& McCormick, S. D. (1999). The effect of migration distance and timing on metabolic enzyme activity in an anadromous clupeid, the American shad (Alosa sapidissima). Fish Physiology and Biochemistry 20, 163-179.

McCormick, S. D. \& Naiman, R. J. (1985). Hypoosmoregulation in an anadromous teleost: influence of sex and maturation. Journal of Experimental Zoology 234, 193-198.

Mulcahy, M. F. (1970). Blood values in the pike Esox lucius L. Journal of Fish Biology 2, 203-209.

Sano, T. (1960). Haematological studies of the culture fishes in Japan. 3. Changes in blood constituents with growth of rainbow trout. Journal of Tokyo University of Fisheries 46, 77-87.

Steuke, E. E. \& Atherton, C. R. (1965). Use of microhaematocrit values to sex largemouth bass. Progressive Fish Culturist 27, 87-89.

Thorarensen, H., Gallaugher, P. \& Farrell, A. P. (1996). Cardiac output in swimming rainbow trout, Oncorhynchus mykiss, acclimated to seawater. Physiological Zoology 69, 139-153.

Thorarensen, H., Young, G. \& Davie, P. S. (1996). 11-Ketotestosterone stimulates growth of heart and red muscle in rainbow trout. Canadian Journal of Zoology 74, 912-917.

Van Kampen, E. G. \& Zijlstra, W. G. (1961). Standardization of hemoglobinometry. II. The hemoglobincyanide method. Clinica Chimica Acta 6, 538.

Videler, J. J. \& Nolet, B. A. (1990). Cost of swimming measured at optimum speed: scale effects, differences between swimming styles, taxonomic groups and submerged and surface swimming. Comparative Biochemistry and Physiology 97A, 91-99.

Yamamoto, K. (1987). Contraction of spleen in exercised cyprinid. Comparative Biochemistry and Physiology 87A, 1083-1087.

Yamamoto, K. (1988). Contraction of spleen in exercised freshwater teleost. Comparative Biochemistry and Physiology 89A, 65-66. 
Yamamoto, K. \& Itazawa, Y. (1989). Erythrocyte supply from the spleen of exercised carp. Comparative Biochemistry and Physiology 92A, 139-144.

Young, P. S. \& Cech, J. J., Jr (1994). Optimum exercise conditioning velocity for growth, muscular development, and swimming performance in young-of-the-year striped bass (Morone saxatilis). Canadian Journal of Fisheries and Aquatic Sciences 51, $1519-1527$. 